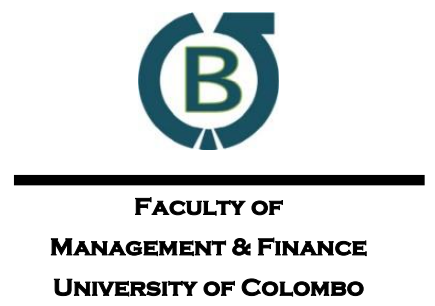

Colombo

Business

Journal

INTERNATIONAL JOURNAL OF

THEORY \& PRACTICE

Vol. 12, No. 01, June, 2021

\title{
Emotional Labour of 'Angels': The Performances and Experiences of Male and Female Nurses in Sri Lanka
}

\author{
S. D. K. Wanninayake ${ }^{\mathrm{a}} \bowtie$, Michael Edward O'Donnell ${ }^{\mathrm{a}}$ \\ ${ }^{a}$ School of Business, University of New South Wales, Australia
}

\begin{abstract}
Despite emotional labour being categorised as women's work or 'pink-collar duties', whether women and men perform and experience emotional labour differently remains an ongoing debate. Most extant studies have explored this phenomenon in Western contexts, with limited research in non-Western contexts. Therefore, this paper explores how male and female nurses performed and experienced emotional labour in a non-Western context, namely Sri Lanka. Utilising 56 interviews with nurses, this qualitative study found that though nursing was perceived as women's work in Sri Lanka, there were instances where female nurses performed stereotypically 'masculine' emotional labour and vice versa. However, constant exposure to service recipients' aggression, psychologically 'taking work home', and having to combine household and caring responsibilities led female nurses to suffer greater emotional exhaustion than men.
\end{abstract}

Keywords: Emotional Labour, Gender, Nursing, Sri Lanka

Received:

13 December 2020
Accepted revised version:

06 May 2021
Published:

30 June 2021

Suggested citation: Wanninayake, S.D.K. \& O’Donnell, M.E. (2021). Emotional labour of 'angels': The performances and experiences of male and female nurses in Sri Lanka. Colombo Business Journal, 12(1), 87-113.

DOI: http://doi.org/10.4038/cbj.v12i1.72

(C) 2021 The Authors. This work is licensed under a Creative Commons Attribution 4.0 International License which permits unrestricted use, distribution, and reproduction in any medium, provided the original work is properly cited.

\ananja.Wanninayake@hrm.cmb.ac.lk iD https://orcid.org/0000-0003-2808-3226 


\section{Introduction}

This study explored how male and female nurses performed and experienced emotional labour in Sri Lanka's public and private hospitals. Emotional labour involves the effort, planning, and control required by employees to modify their expression of emotions for a wage to meet the expectations of both employers and customers (Ashforth \& Humphrey, 1993; Bartram et al., 2012; Hochschild, 1983).

Emotional labour is often portrayed as gendered. Firstly, emotional labour has been stereotyped as associated with women's work because men often undertake more privileged and economically viable roles while women undertake a higher proportion of nurturing, caring, or service responsibilities, also known as 'matters of the heart' (Evers, 2018; Lively, 2013). However, this idea overlooks several significant aspects - emotional labour is performed by men in stereotypically 'masculine' and male-dominated industries (Thurnell-Read \& Parker, 2008; Vaccaro et al., 2011; Yarnal et al., 2004) as well as in female-dominated and stereotypically 'feminine' occupations (Cottingham, 2015; Simpson, 2004); also some performances of emotional labour may require stereotypically 'masculine' emotions, such as intimidation or aggression (Ward \& McMurray, 2016; Ward et al., 2020).

Secondly, women are often perceived to be victims of emotional labour because they are seen to suffer higher levels of stress and burnout compared to male employees (Cottingham et al., 2015; Martin, 1999; Vincent \& Braun, 2013). In contrast, studies such as (Bulan et al., 1997) have revealed that women may be better equipped to handle the interpersonal demands of frontline jobs than their male colleagues because service work is largely similar to women's traditional caretaking role. Additionally, Erickson and Ritter (2001) found that the experiences and consequences of emotional labour are not gender-based, but emotion-based. Since most of the extant studies (Cottingham et al., 2015; Cottingham et al., 2018; Elliott, 2017; Søgaard \& Krause-Jensen, 2020; Thurnell-Read \& Parker, 2008; Torland, 2011; Ward et al., 2020) have explored the gendered nature of emotional labour in Western contexts, little is known on the same in non-Western cultural contexts (Brooks \& Devasahayam, 2010; Nixon et al., 2011; Pandey et al., 2018; Syed \& Ali, 2013; Yang \& Guy, 2015). To bridge this gap, this study explored how male and female nurses performed and experienced emotional labour in public and private hospitals in Sri Lanka.

\section{Emotional Labour, Gender, and Nursing}

Service work involves combined physical, cognitive and emotional challenges. Employees are expected to display organisationally desired emotions in face-to-face 
and voice-to-voice customer interactions (Kim \& Han, 2009; Shani et al., 2014). This element of emotion work in service encounters has been labelled 'emotional labour' (Hochschild, 1983).

Research on emotions began in the 1970s in the fields of Sociology and Psychology and became an area of inquiry in the Business Management literature in the 1980s with the seminal work of Hochschild (1983) on emotional labour, The Managed Heart: Commercialization of Human Feeling. Hochschild's (1983) study, which focused on flight attendants and bill collectors revealed that service sector employees were expected to perform a new kind of labour referred to as 'emotional labour'. In performing emotional labour, employees were expected to exchange their emotions and feelings for a wage, transforming their emotions and feelings into commodities (Watson \& Ward, 2013). Hochschild's (1983) social theory on emotions and feelings, also known as emotion management theory (Cottingham, 2015) gave birth to a new wave of research on work in the service sector.

Hochschild $(1979,1983)$ distinguished between the two concepts, emotion work, and emotional labour. Emotion work is described as "the act of trying to change in degree or quality an emotion or feeling" within oneself (Hochschild, 1979, p. 561) or the "management of feeling to create a publicly observable facial and bodily display" in private spheres of life such as with friends and family (Hochschild, 1983, p. 7). Though emotion work is a process that takes place within oneself, emotion work becomes an object of awareness when one's feelings do not fit the situation and individuals often try to make their feelings consistent with the situation (Hochschild, 1979).

Emotion work becomes emotional labour when the emotions previously displayed in private spheres of life are taken to the marketplace and sold by organisations as human labour for a profit motive (Hochschild, 1983). Emotional labour treats emotions as a commodity that is sold for a wage (Hochschild, 1983). In transferring the emotion management process from the private sphere to a public sphere, individuals are expected to carry out acts of emotion management under the guidance of "feeling rules" prescribed by organisations (Hochschild, 1983, p. 19). Feeling rules, referred to as display rules in the subsequent literature, include standards that govern the emotional displays of individuals to determine the type of emotions people are expected to express, for example, happiness, friendliness, or intimidation (Ashforth \& Humphrey, 1993; Hochschild, 1983; Theodosius, 2008). These rules act as norms to specify the type and amount of feeling to be experienced and displayed in specific work situations (Wharton, 2009). 
Performance of emotional labour may result in surface or deep acting. Surface acting involves trying to change how one outwardly appears by modifying emotional displays without shaping inner feelings (Grandey, 2003; Hochschild, 1983). In surface acting, workers try to stimulate unfelt emotions and/or supress felt emotions through careful use of verbal and nonverbal cues such as facial expressions, gestures and voice tone (Ashforth \& Humphrey, 1993; Bozionelos \& Kiamou, 2008). In deep acting, individuals display "a natural result of working on feeling; the actor does not try to seem happy or sad but rather expresses spontaneously... a real feeling that has been self-induced" (Hochschild, 1983, p.35). Individuals could deep act by either exhorting feelings or by using emotion memories (Hochschild, 1983; Theodosius, 2008). Exhorting feelings includes individuals trying to actively evoke or supress an emotion (Ashforth \& Humphrey, 1993). For example, a hotel receptionist empathising with an aggressive customer. Individuals may also use emotion memories, for example, when one needs to display happiness or excitement, the employees may think of a situation in their life that brought happiness or excitement and imagine that it is 'really happening now' (Hochschild, 1983, p. 42). Workers expressing their real emotions may also be a method of performing emotional labour (Ashforth \& Humphrey, 1993; Kim \& Han, 2009). This is known as genuine acting, automatic regulation or authentic displays (Chu et al., 2012; Grandey \& Melloy, 2017).

Performing emotional labour improved employees' ability to cognitively distance themselves from negative incidents (Ashforth \& Humphrey, 1993; Chu et al., 2012; Hochschild, 1983). However, the need to display inauthentic emotional expressions may make workers feel false, hypocritical and suffer emotional dissonance (Ashforth \& Humphrey, 1993; Theodosius, 2008). Emotional dissonance represents "the state of discomfort, unease, tension, or psychological strain due to discrepancies between felt and expressed emotions or due to discrepancies between felt and organisationally desired emotions" (Mishra \& Bhatnagar, 2010, p. 403). Emotional dissonance often lead to job burnout where workers feel they are no longer able to give of themselves at the required psychological level (Holland et al., 2013).

Emotional labour is perceived to be gendered from different dimensions though findings remain contradictory. Firstly, emotional labour is often stereotyped as women's work because of the perception that women possessed a natural tendency towards compassion, care, community orientation, and understanding (Cottingham et al., 2018; Elliott, 2017), women's natural capabilities of 'mothering' and caretaking (Lawless, 2018) and the notion that men undertook more economically viable roles 
(Erickson \& Ritter, 2001; Evers, 2018; Taylor \& Tyler, 2000). The connection between emotional labour and women has been strongly established to an extent that tasks involving emotional labour are often referred to as 'pink-collar duties' in the literature (Lawless, 2018). However, categorising emotional labour as women's work is misleading. Such a categorisation only considers empathetic performances of emotional labour that require stereotypically 'feminine' emotions such as care and compassion and overlooks antipathetic performances of emotional labour which require stereotypically 'masculine' emotions, such as intimidation or aggression (Ward \& McMurray, 2016, p. 9) which may be performed by both men and women. Such stereotyping of emotional labour also ignores the gendered way men engage in emotional labour in male-dominant occupations such as firefighting (Evers, 2018) where men were often expected to follow display rules and surface act to hide their feelings of fear, stress, or frustration (Thurnell-Read \& Parker, 2008; Vaccaro et al., 2011; Yarnal et al., 2004).

Secondly, because women are more vulnerable to others' negative emotions than men (Wharton, 1993), and they are often subjected to subordination by service recipients at workplaces (Forseth, 2005), it is perceived that women suffer more negative consequences of performing emotional labour than men (Cottingham et al., 2015; Johnson \& Spector, 2007). Hochschild (1983) was the first to project women as victims of emotional labour. Hochschild (1983) revealed that the historical subordination of women has left them with a weaker 'status shield' and made them easier targets of rudeness, verbal abuse, and bigotry than their male counterparts. For example, in service industries such as banks and call centres, female service employees often experience higher incidences of customer abuse than their male counterparts (Forseth, 2005; Korczynski, 2003).

On the other hand, due to women's socialisation process, and the similarity between their traditional caretaking role and frontline service work, it is perceived that women were often better than men in handling interpersonal demands of frontline jobs (Bulan et al., 1997; Wharton, 1999). Further, projecting women as victims of emotional labour ignores the detrimental effects men may also face when performing emotional labour. Many male employees also suffer when they are expected to display unfelt emotions or suppress felt emotions, especially in male-dominant professions such as firefighting, working as butchers or engaging in edgework, also known as social control work such as police and prison (Evers, 2018; Simpson et al., 2011; Thurnell-Read \& Parker, 2008; Torland, 2011; Vaccaro et al., 2011; Yarnal et al., 2004, Ward et al., 2020). 
Thirdly, most of the studies conducted on emotional labour including Hochschild's (1983) study on flight attendants, have focused on emotional labour in female-dominant and stereotypically 'feminine' industries (Erickson \& Ritter, 2001; Pruitt, 2012). Limited research has been undertaken on women's experiences in stereotypically 'masculine' industries (Martin, 1999; Pruitt, 2012) or men's experiences in stereotypically 'feminine' industries (Gray, 2010; Simpson, 2004). Being in stereotypically 'feminine' and numerically female-dominant occupations have led men to enjoy benefits. For example, male teachers and male nurses have received heightened visibility and have been perceived to possess leadership qualities and expertise in their job roles (Simpson, 2004). In addition, White men who worked in stereotypically 'female' occupations have experienced faster career progression to management positions referred to as the "glass escalator" (Maume, 1999, p. 501).

Men may also struggle with the fear of having their sexuality questioned when they work in female-dominated and stereotypically 'feminine' occupations and industries (Evans, 2004; Evers, 2018; Gray, 2010; Nixon, 2009). For example, men in stereotypically 'feminine' occupations such as teaching and nursing often suffered anxiety which was associated with implications of homosexuality and sexual perversion (Simpson, 2004, p. 361). In response, these men adopted strategies that seek to maintain their masculinity, for instance, male librarians have re-labelled themselves as "information scientists" or "researchers" (Simpson, 2004, p. 359).

Emotional labour in different national contexts also remains under-explored (O'Donohoe \& Turley, 2006; Syed \& Ali, 2013). Individuals' emotions, thoughts and actions are largely context-bound and vary with organisational and societal norms (Syed \& Ali, 2013). To date, emotional labour has primarily been investigated in North America, Europe and other Western contexts; therefore, the contextual and nuanced nature of emotional labour, particularly in the Asian context, remains underexplored (Babatunde et al., 2021; Bozionelos, 2016; O'Donohoe \& Turley, 2006; Syed \& Ali, 2013; Syed et al., 2006). To bridge this gap, this study explored how male and female nurses performed and experienced emotional labour in Sri Lanka's public and private hospitals.

Nursing has been stereotyped as a feminine profession. The image of nurses emphasises caring mothers, angels and nurturers (Gray, 2010; Simpson, 2004). Nurses in healthcare were often confronted with emotional challenges such as demanding patients, time pressures and work overload (Bartram et al., 2012; Theodosius, 2008). Nurses' experiences of constantly regulating their emotions have 
been researched mostly in Western hospital contexts (Bartram et al., 2012; Delgado et al., 2020; Delgado et al., 2017; Theodosius et al., 2021). A number of studies have explored nurses' experiences of managing their emotions in Asian contexts such as Korea (Han et al., 2018; Kim \& Jang, 2018), India (Roopalekha et al., 2012; Thomas \& Abhyankar, 2014), Iran (Zamanzadeh et al., 2013), China (Liu et al., 2020; Zhou et al., 2015) and Pakistan (Banning \& Gumley, 2012). Emotional labour in Sri Lanka is heavily under-researched where a few studies have explored emotional labour among school teachers (Dias \& Bhadra, 2014), bank tellers (Kodikara \& De Alwis, 2015; Perera \& Arachchige, 2014), academics in state universities (Thisera \& Bandara, 2018), and cabin crew and frontline airport staff (Perera \& Kailasapathy, 2013). Further, though studies have explored the impact of staff shortages, health and safety issues, and poor working conditions as well as the influence of gender, ethnicity, class, race, and unionism on nursing in Sri Lanka (De Silva \& Rolls, 2010; Hellerawa \& De Alwis, 2015; Jayasekara \& Schultz, 2007; Pinto \& Adikaram, 2020), the emotional labour component of nursing remains under-explored (Thisera \& Silva, 2017; Wanninayake, 2018).

\section{Research Context}

Sri Lanka's healthcare sector included both public and private healthcare services. Public healthcare services were offered free of charge via a wide range of national, provincial, base and district hospitals and health care units (Abeykoon, 2003; Jayasekara \& Schultz, 2007). The Sri Lankan government allocated LKR 244.3 billion for healthcare and employed 38, 276 nurses across 603 public hospitals with a total bed capacity of 77, 964 (Central Bank of Sri Lanka (CBSL), 2019). Private healthcare services provided inpatient care from the 1980s following the reintroduction of private practice by public-sector doctors, liberalisation of drug imports and overcrowding in public hospitals (Abeykoon, 2003). By the year 2020, the private healthcare sector employed 2, 389 nurses who were registered with the Private Health Services Regulatory Council (PHSRC) (PHSRC, 2021) across 207 registered private hospitals with a total bed capacity of 5,147 (CBSL, 2019). Most of the private hospital nurses were not registered (Aluwihare-Samaranayake et al., 2017; Jayasekara \& Mccutcheon, 2006) and statistics of this group are not available.

Shortage of nurses is a significant issue in Sri Lanka's healthcare system (Aluwihare-Samaranayake et al., 2017). The nursing density in Sri Lanka is 21.8 per 10,000 population and it is substantially low when compared to more economically advantaged countries including Australia (125.5 per 10, 000 population), the United Kingdom ( 81.7 per 10, 000 population), Canada (99.4 per 10,000 population), and 
Germany (132.4 per 10, 000 population) (World Health Organization, 2020). This shortage of nurses is a result of nursing being an unattractive profession because of low pay, poor working conditions, long working hours, limited career progression and inadequate professional recognition in Sri Lanka (Aluwihare-Samaranayake et al., 2017; Aluwihare-Samaranayake et al., 2018).

Working overtime was compulsory especially for Sri Lankan public sector nurses because of staff shortages. Hellerawa and De Alwis (2015) found that 66.7 per cent of nurses in Sri Lankan public hospitals had to do more than regular overtime hours to make up the minimum nursing workforce numbers. Sri Lankan nurses had to deliver patient care, administer medications, coordinate paramedical activities, supervise junior nurses and assistant staff members and attend to non-patient care activities including maintaining ward statistics, nursing administration and housekeeping duties (De Silva \& Rolls, 2010). This increased workload led to emotional exhaustion, work-life imbalance and provided nurses with less time to interact with patients, or to deliver care (Hellerawa \& De Alwis, 2015).

\section{Methods}

\section{Selection of Participants and Data Collection Strategies}

This social constructionist study explored how male and female nurses performed and experienced emotional labour in Sri Lanka's public and private hospitals. The qualitative data from public and private hospitals were collected through 56 semistructured, face-to-face interviews with male and female nurses that lasted between 30-90 minutes. The participants were purposively selected by considering if they were attached to a fully-fledged public or a private hospital (not a nursing home or a dispensary) and were serving as permanent nurses. During the study, they were attached to medical and surgical ward, merchants' ward, intensive care unit, neonatal intensive care unit, eye hospital, emergency treatment unit, dialysis unit, orthopaedic ward, paediatric ward, dermatology unit, maternity ward, neurotrauma unit and the operating theatre. Most public hospital nurses possessed work experience in multiple hospitals and medical units as they were periodically transferred across medical units of the same hospital as well as other teaching, provincial, base, and district hospitals. Out of the private hospital nurses, five were retirees from the public sector, nine had worked only in one hospital and others possessed work experience in multiple private hospitals. The initial respondents of the study were requested to introduce other participants in their field of work who were willing to participate in the study. Participants' profile is provided in Table 1. 
Table 1: Participants' Profile

\begin{tabular}{lccc}
\hline & Female & Male & Nursing experience \\
\hline Public sector & 15 & 11 & 4.5 years to 26 years \\
Private sector & 20 & 10 & 1.5 years to 40 years \\
Total & 35 & 21 & \\
\hline
\end{tabular}

Data collection was through interviews which were conducted in 2016 (17 interviews with private hospital nurses and 14 interviews with public hospital nurses) and 2018 (13 interviews with private hospital nurses and 12 interviews with public hospital nurses). The second round of interviews was conducted to gather further indepth information and insights related to the themes that emerged from the data collected during the first round. The themes that emerged were not participantspecific, therefore, during the second round, the interviews were conducted with participants who could be contacted from the first round (four private and five public hospital nurses) together with new participants. During the second round, the interviewer discussed the preliminary findings of the first round of interviews with nurses who participated in both rounds to ensure that their experiences and performances were captured accurately.

The Sri Lankan researcher (i.e., the first author) conducted all interviews. A few participants were conversant in English, and even the ones who were not conversant in English were able to communicate medical terms and procedures in English. The researcher who conducted the interviews being a Sinhala speaking Sri Lankan, a 'cultural insider' according to Liamputtong (2008), was able to translate the interviews from Sinhala to English. Further, the researchers verified the claims made in Sinhala with other nurses who were conversant in English and Sinhala languages to reduce the scope for misinterpretation. The study was conducted based on the ethics approval issued by the Ethics Committee of the University of New South Wales, Canberra, Australia.

\section{Data Analysis}

To analyse data thematically, the researchers followed Braun and Clarke's (2006) six-step approach. The digitally recorded interviews were transcribed verbatim. Using NVivo as a data management tool, researchers generated the initial codes. Thereafter, the researchers collated these open codes that emerged from the transcripts into broader categories. These broader categories were then collated into themes which were later refined to ensure that they cohered together meaningfully and that there were clear and identifiable distinctions between the themes. Three key 
themes that emerged from the interviews include gendered nursing, emotional performances of male and female nurses, and women more burnt-out than men. Finally, a detailed analysis was undertaken for every theme identified above to develop the narrative revealed by each theme and findings were appropriately documented. Table 2 provides an example of the data analysis process.

Table 2: Example of the Data Analysis Process

\begin{tabular}{|c|c|c|c|}
\hline Data Example & $\begin{array}{l}\text { Examples of Initial } \\
\text { Codes }\end{array}$ & $\begin{array}{l}\text { Broader } \\
\text { Categories }\end{array}$ & Theme \\
\hline $\begin{array}{l}\text { When we got registered, they } \\
\text { registered male nurses as part B } \\
\text { and female nurses as Part A. } \\
\text { This is because we cannot do } \\
\text { midwifery...male nurses are not } \\
\text { sent to the labour room even } \\
\text { with superiors' permission... } \\
\text { We are never allocated to } \\
\text { gynaecology and obstetrics } \\
\text { wards... During our nurses' } \\
\text { training when girls were taught } \\
\text { that subject, we were asked to } \\
\text { leave the class to go to the } \\
\text { wards...male nurses cannot do } \\
\text { procedures of female patients.... } \\
\text { When it comes to decision } \\
\text { making and handling difficult } \\
\text { patients, female nurses are a } \\
\text { little scared. Then we get } \\
\text { involved } \\
\text { (Male nurse, } 16 \text { years, } \\
\text { emergency unit, public sector) }\end{array}$ & $\begin{array}{l}\text { No midwifery training } \\
\text { for men } \\
\text { Men don't handle } \\
\text { women's procedures } \\
\text { Men handle aggression }\end{array}$ & $\begin{array}{l}\text { Men do } \\
\text { physically } \\
\text { demanding } \\
\text { work }\end{array}$ & $\begin{array}{l}\text { Gendered } \\
\text { nursing }\end{array}$ \\
\hline
\end{tabular}

\section{Findings}

\section{Gendered Nursing}

A strongly engrained perception among Sri Lanka's nurses was that nursing is a 'feminine' occupation. Participants revealed that patients often did not believe that a man could be a nurse, or that there are male nurses. They viewed men in nurses' uniforms as either doctors or attendants especially in the public sector. Some female participants perceived that nursing was not a suitable profession for men. One participant stated,

... When you take a female nurse, it's common in society. People identify the uniform. But we are not very popular...Some people don't know the term 'male nurse'. Most 
patients...call us 'doctor' or 'attendant'. Then we have to correct them and say I am a nurse. But they don't believe. They think nursing is a job of a woman... (Male nurse, 16 years, emergency unit, public sector)

Caregiving, and nursing being viewed as stereotypically 'feminine' roles led to gendered job allocations, perceptions on male nurses' inability to emotionally connect with patients, and sexual taboos in nursing. Male nurses were often allocated to physically demanding job roles which were considered to be stereotypically 'masculine' and required the expression of stereotypically 'masculine' emotions. For example, handling psychiatric patients. Additionally, male nurses were never allocated to maternity or paediatric wards which were considered as stereotypically 'feminine' tasks and Sri Lanka's male nurses often did not receive training on midwifery. Some participants perceived that male nurses were unable to develop an appropriate emotional bond with children to work in paediatric wards. Further, it was considered as culturally inappropriate for male nurses to handle medical procedures of women or be present during such procedures which created a barrier for male nurses to emotionally connect especially with female patients. Some patients refused the services of male nurses as they perceived that female nurses were 'gentle' and conducted medical procedures without 'hurting' them. One participant revealed,

In paediatric wards, when you have to give medicine to kids, they [male nurses] sometimes do not understand how to talk to the kids properly. If it's a female nurse, she would know how to tell a lie and get the child to take the medicine. But male nurses find it a little difficult... Most patients like female nurses. They are gentle with patients. But male nurses when compared to female nurses are a bit rough... (Female nurse, 6 years, paediatric ward, private sector)

\section{Emotional Performances of Male and Female Nurses}

Despite nursing being viewed as women's work, there were instances when female nurses engaged in stereotypically 'masculine' emotional performances and vice versa. Firstly, the majority of female nurses demonstrated negative emotions to prevent male patients subjecting them to harassment (with the exception of some junior female nurses who were hesitant to show negative emotions to patients, relatives or bystanders ${ }^{1}$ because they were reluctant to be recipients of harsh verbal or physical responses). For example, senior female nurses often raised their voices with male patients to limit any potential sexual or verbal harassment from them. In the emotional labour literature, expressing emotions such as dominance, anger, and

\footnotetext{
${ }^{1}$ A term used by Sri Lankan nurses to describe people hired by patients' relatives to take care of hospitalised patients. In most cases, they would be retired healthcare employees such as hospital attendants or labourers.
} 
irritation have been associated with men's work (e.g., police, guards, bill collectors, bouncers), or as masculinity at work (Humphrey et al., 2008; Ward \& McMurray, 2016). This expression of stereotypically 'masculine' emotions was prevalent among public hospital nurses. It was because private hospital nurses performed a caring cum customer service role and were expected to serve with a smile, and be courteous to patients at all times to avoid negative feedback. One male nurse interviewed noted:

...With experience some female nurses know that certain patients have to be told things sternly. Then they change their tone to an aggressive one...male nurses are anyway strict. But junior female nurses can be affected. If there is a junior female nurse, they try to maintain a cordial relationship with patients and bystanders... (Male nurse, 8 years, orthopaedic ward, public sector)

Male nurses, on the other hand, revealed that they often used surface acting to show stereotypically 'feminine' emotions such as sympathy or empathy to patients or patients' family members. However, there were instances when male nurses also were able to induce empathy and sympathy without an effort towards patients or their families. One male nurse stated,

...My father died of...colon cancer. When I see a cancer patient, I feel that it is my father. Automatically I care very much for cancer patients. I get very emotional with cancer patients. I have seen how my father spent his life and I feel the same would happen to this patient... (Male nurse, 14 years, intensive care unit, private sector)

Secondly, most patients and their relatives preferred to share their experiences and problems with female nurses. The participants revealed that patients preferred to be distant with male nurses because men were often kept at a 'higher level' in the society which made them feel uncomfortable to share their issues and concerns. For example, one nurse stated,

Male nurses are also loving and caring. But women are closer with patients. Patients tell us any problem they have...men...we tend to keep them at a higher level in society. For example, if we take the two of us [referring to the female interviewer], I can tell you my problems simply because you are a woman. There is something like that... (Female nurse, 16 years, neonatal intensive care unit, private sector)

However, there were many instances where male nurses also formed close emotional bonds with patients, especially when they were hospitalised for longer periods. For example, in addition to patients sharing details of their illnesses, personal and family issues that concerned them, some male nurses were requested to attend to confidential matters of patients such as their banking and documentation relating to financial activities which required a deep level of trust and confidence. One male nurse stated, 
...When patients are there for a long-time period, we develop emotional contact with them. Even in our ward, there were patients who were there for a few months. They sometimes tell their personal issues with us... (Male nurse, 10 years, medical ward, public sector)

\section{Female Nurses More Burnt-out Than Male Nurses}

The consequences of emotional labour effected female nurses more negatively than many male nurses. Firstly, public and private sector female nurses tended to experience a higher level of verbal aggression by patients, relatives and bystanders than male nurses. In the private sector, patients and their families attempted to impose a level of control over nurses because they paid for their treatment. In the public sector, patients became verbally aggressive because of inadequate facilities such as hospital beds and to gain personal attention from nurses who often handled 25-30 patients during a daytime shift and over 50 patients during a night shift. Additionally, in public hospital wards, some male patients passed sexualised comments, or removed their clothes when female nurses were doing ward rounds. Public hospital female nurses revealed that their uniforms, which was a knee-length frock, fuelled such behaviour because they had to lift and turn patients for medical procedures which was awkward while wearing this dress. In the private sector, male patients complained of fake aches and pains or rang the calling bell unnecessarily to get female nurses to visit their rooms and inappropriately touched them when performing medical procedures. Being subjected to verbal and sexual harassment increased the levels of emotional exhaustion among female nurses because they were under constant pressure to supress negative emotions. One female nurse highlighted,

...Some old patients pass dirty comments... There are certain patients who remove their clothes when they feel we are coming... We feel ashamed because we are ladies. We just ignore the patient. If we scold the patient, the other patients will get to know what he told... (Female nurse, 10 years, medical ward, public sector)

Further, immediately after being subjected to verbal or sexual harassment, there were instances where nurses were expected to appear empathetic or courteous towards patients or families especially in the private sector. This required rapid changes of emotional performances that involved significant levels of flexibility in emotion management that led to emotional strain. Public and private male nurses, on the other hand, possessed a superior status to female nurses which gave them an 'emotional status shield'. The fear and obedience patients and their relatives showed towards male nurses often led to a gendered division of nursing roles where male nurses were expected to perform a patriarchal role of handling patient and family aggression and controlling patient harassment. As one nurse revealed, 
...sometimes it's easy for male nurses to handle patients. Simply because they are men... (Male nurse, 12 years, medical and surgery ward, private sector)

Secondly, male nurses were often better at distancing their professional lives from their personal lives. Many female nurses would often bring work issues home with them after their shifts and continue to be concerned about patient welfare and related issues. One female nurse stated,

Female nurses keep everything in their minds... I suffer sometimes when I can't tell my issues to someone... I also kept remembering the patients when I went home... Then I used to suffer mentally and it was difficult to make up my mind to come to work the next day... I had no other option... (Female nurse, 26 years, dermatology unit/merchants' ward, public sector)

Male nurses appeared better able to create a separation between their work and home lives which reduced the level of emotional distress they experienced. A male nurse noted,

It took me several years to understand this job fully... But now, with time, I have realised that this is just my job and I have a separate personal life. So now I can balance both well... I don't try to mix up my personal life with my professional life. It may be because I am a male nurse. I don't have much responsibilities at home as my wife looks after the household. So, I can do my job well. (Male nursing supervisor, 21 years, emergency treatment unit/acting chief nursing officer, private sector)

Further, male nurses often appeared calmer when handling emergency situations than female nurses. In addition, male nurses were often perceived to make faster decisions during emergency situations and voice their opinions on medical treatment with medical doctors than female nurses. One female nurse stated,

...Male nurses are different. They are relaxed during the shift. They don't get stressed like we do... They can detach themselves better from the profession than female nurses. (Female nurse, 26 years, dermatology unit/merchants' ward, public sector)

Thirdly, especially in the public sector, the stress of working long hours and not being able to take leave for personal needs often affected female nurses more than male nurses. For example, in certain hospital units, when nurses started work at one pm, they often completed the night shift and were entitled to leave by seven am the following day which was their sleeping day. However, they did not morally feel that they could leave the hospital and let relatively few nurses handle a large number of patients. Therefore, they continued until one pm on their sleeping day. Or when nurses came for their night shift that starts at seven pm, they continued until seven pm the following day. Due to continuous work shifts, female nurses had to neglect 
their children and were unable to fulfil their family and household responsibilities which further drained them emotionally. One male nurse stated,

Now when you take other professions like clerical or teaching, they have holidays. But for us there is nothing like that. For me I don't have an issue because my wife is not working for the healthcare sector. So, looking after my son is easy. Others are under tremendous stress because with night duty it is difficult to maintain the work family balance. The other thing is it is difficult to take leave. Even if a child is sick, it's difficult to take leave. Then the person who is working is under stress... (Male nurse, 20 years, infection control/medical, public sector)

\section{Discussion}

Sri Lanka's nurses perceived nursing as women's work and a stereotypically 'feminine' profession as found in most other contexts (Cottingham, 2015; Gray, 2010; Qureshi et al., 2020). Confirming prior research (Cottingham, 2015; Simpson, 2004, 2007), this study revealed that allocation of job roles and clinical areas were gendered where female nurses handled stereotypically 'feminine' maternity or paediatric wards while male nurses handled stereotypically 'masculine' psychiatric or medical wards. In Sri Lanka, this gendered division was backed by the perception that male nurses were incapable of developing emotional contact with patients while female nurses were 'gentler'. On the one hand, this perception led to refusal of services of male nurses by patients and also, made it challenging for male nurses to emotionally connect with patients as found in prior studies (Gray, 2010). On the other hand, this study added that female nurses were under tremendous pressure to constantly meet the expectations of being 'nicer than natural' by displaying comforting behaviours which is identified in the literature as 'flight attendant type emotional labour' (Erickson \& Ritter, 2001; Greenhalgh et al., 1998; Koster, 2011; Martin, 1999; Taylor $\&$ Tyler, 2000) or empathetic emotional labour (Ward \& McMurray, 2016).

While there were gendered expressions of emotional labour in Sri Lanka's healthcare sector, there were also instances where female nurses expressed stereotypically 'masculine' emotions such as dominance, anger, and irritation (Humphrey et al., 2008; Ward \& McMurray, 2016) when dealing with overly demanding patients, relatives, or bystanders. In addition, there were instances when Sri Lanka's male nurses formed deep emotional connections with patients, a stereotypically 'feminine' trait (Greenhalgh et al., 1998). These findings highlighted the dangers of attributing stereotypical emotional performance to men and women, and of using these binary categories which serve to reinforce gendered norms. They further elaborated the importance of not 'glossing over' differences in performances of emotional labour by employees of the same gender (Kelan \& Nentwich, 2009). 
However, more of Sri Lanka's male nurses demonstrated stereotypically 'masculine' emotions towards patients and their relatives. Men in hospital settings were able to express anger while women were more restrained in line with Sri Lanka's patriarchal culture. In the emotional labour literature, this advantage experienced by men is referred to as a status shield (Hochschild, 1983), or status bonus (Cottingham, 2015). In addition, male nurses in Sri Lankan hospitals were perceived to be calmer during emergency situations than female nurses and they appeared more confident of their technical skills. Further, they often preferred to voice their opinions on medical treatment with medical doctors. On the one hand, male nurses' confidence on their technical skills provided them with an emotional buffer to conquer their negative feelings, such as fear and stress when responding to life-threatening incidents on hospital wards (Cottingham, 2015). On the other hand, this behaviour helped male nurses to align themselves with men of a higher status than themselves (male doctors in this case) which they used as a technique to maintain their 'masculine' identity in a stereotypically 'feminine' occupation (Evers, 2018; Simpson, 2004). Female nurses, however, experienced limited job autonomy and were expected to follow medical doctors' instructions without question. This finding confirmed claims by Vithanage (2015) that norms of patriarchy in Sri Lanka often treated women as subordinates and constrained their willingness to voice their opinions in the workplace.

The perception of men being more agentic, competent and worthy of higher status tended to enhance women workers' negative experiences of emotional labour (Cottingham et al., 2015; Johnson \& Spector, 2007). Female nurses in public and private hospitals in Sri Lanka were subjected to greater verbal aggression and sexual harassment by patients, relatives and bystanders than male nurses. Patients and relatives were also more obedient when instructions were given by male nurses. This finding supports other research that female nurses in healthcare settings were at increased risk of sexualised violence and harassment than other employees (Jackson et al., 2013). In Sri Lanka, nurse managers and senior hospital managers failed to develop a "zero-tolerance approach to sexualised and gendered abuse" as found in other contexts (Jackson et al., 2013, p. 2072). Further, the findings confirmed that men in female-dominated and stereotypically 'feminine' occupations tended to enjoy an "assumed authority effect" where they were often expected to be disciplinarians and to take charge of demanding situations or conform to a 'muscle-man' role, and to take up physically demanding job roles (Simpson, 2004, p. 363).

Female nurses suffered higher levels of emotional exhaustion than male nurses. In this case, frequent experiences of misbehaviour by patients and families, inability 
to distance their work from personal lives, and experiences of work-family imbalance due to continuous work shifts led to high levels of emotional exhaustion and job burnout among female nurses. Verbal and sexual harassment by patients and families targeting female nurses was present in Western healthcare settings as well (Jackson et al., 2013; Stone et al., 2011). This constant exposure to verbal and sexual harassment, on the one hand, required female nurses to often surface act by supressing negative emotions to express appropriate positive emotions and on the other hand, expected female nurses to engage in diverse emotional performances that needed rapid changes in emotion management referred to as "emotion switching" in the literature (Ward \& McMurray, 2011, p. 1586) that led to significant levels of emotional exhaustion. Emotion switching refers to "the process of sequentially managing and performing antithetic emotions in a given context" (Ward \& McMurray, 2011, p. 1586). Additionally, female nurses were less able than male nurses to distance their work from their personal lives, which is referred to as psychologically "taking work home" in the emotional labour literature (Gray \& Smith, 2009, p. 257). Male nurses' ability to distance their care work from personal lives was also evident among male nurses in Western work environments (Cottingham, 2015). Further, in line with previous research (Karimi et al., 2016), this study revealed that work design related factors such as long working hours, staff shortages and heavy workload exacerbated the negative effects of emotional labour. This study added that these negative working conditions affected female nurses more than male nurses because even if Asian women continued employment after marriage, they were still expected to fulfil childcare and housework responsibilities as well as fulfil the requirements of their extended families (Fernando \& Cohen, 2013; Kailasapathy \& Metz, 2012). Overall, female nurses became victims of emotional labour than male nurses and this is in line with prior studies that revealed women suffered more by performing and experiencing emotional labour than men (Cottingham et al., 2015; Hochschild, 1983; Johnson \& Spector, 2007).

\section{Contributions and Future Research Areas}

The findings of this study have several theoretical and practical implications. Firstly, this study extended the theory and literature on gender and emotional labour by highlighting the dangers of attributing stereotypical behaviours to men and women in healthcare settings, and of using binary categories to reinforce gendered norms. Secondly, this study added to the limited research on the contextual and nuanced perspective of performances and experiences of emotional labour in non-Western contexts. From a practical perspective, this study highlighted the impact of emotional labour on nurses depicting the importance of hospital managers and nursing educators 
to implement proper training, education, and practices to counter exploiting nurses' emotions. Additionally, the findings assist authorities to understand the importance of improving working conditions as they exacerbated nurses' negative experiences of emotional labour. Further, understanding the differences in male and female nurses' experiences and performances of emotional labour assists nursing educators to develop programmes to reduce barriers faced by male nurses in developing emotional contact with patients, to enable female nurses to successfully handle emotional exhaustion and to reduce the gendered division of job roles.

The findings suggest many avenues for future research. First, how male and female nurses performed and experienced emotional labour in other non-Western contexts could be explored. Second, this study could be replicated with a different group of frontline healthcare professionals to explore if their emotional labour performances and experiences varied from those of nurses. Third, in-depth research into how service recipients experienced nurses' emotional labour performances would reveal the variety and complexity of emotional labour in healthcare environments.

\section{Conclusion}

This study explored how male and female nurses performed and experienced emotional labour in Sri Lanka's public and private hospitals. Male nurses were perceived to be better at relinquishing control over emotionally challenging situations than female nurses. However, there were instances where female nurses expressed emotions such as dominance and anger, which were categorised as stereotypically 'masculine' emotions and male nurses formed deep emotional connections with patients which was identified as a 'feminine' quality in the emotional labour literature. This highlighted the importance of not attributing stereotypical emotional labour related performances and experiences to men and women in healthcare settings, or considering emotional labour as solely women's work. However, the patriarchal nature of the Sri Lankan society where men are considered to be agentic and worthy of a higher status, while women are expected to display behaviour patterns including respectability and submissiveness have led female nurses to suffer emotional exhaustion.

\section{Declaration of Conflicting Interests}

The authors declared no potential conflicts of interest with respect to the research, authorship, and publication of this article. 


\section{References}

Abeykoon, P. (2003, October 2020). The implications of technology hange for health care delivery in Sri Lanka. https://citeseerx.ist.psu.edu/viewdoc/download?doi=10.1.1.604.1118\&rep=rep1 $\&$ type $=$ pdf

Aluwihare-Samaranayake, D., Ogilvie, L., Cummings, G. G., \& Gellatly, I. R. (2017). The nursing profession in Sri Lanka: time for policy changes. International Nursing Review, 64(3), 363-370. https://doi.org/10.1111/inr.12398

Aluwihare-Samaranayake, D., Gellatly, I., Cummings, G., \& Ogilvie, L. E. (2018). A contextual work life experience model to understand nurse commitment and turnover. Journal of Advanced Nursing, 74, 2053-2063. https://doi.org/10.1111/jan.13718

Ashforth, B. E., \& Humphrey, R. H. (1993). Emotional roles: The influence of identity. Academy of Management Review, 18(1), 88-115. https://doi.org/10.2307/258824

Babatunde, A., Mordi, C., Ajonbadi, H. A., \& Oruh, E. S. (2021). Working with emotions : Cultural employee perspectives to service management expectations. Employee Relations: The International Journal. Advance online publication. https://doi.org/10.1108/ER-11-2020-0489

Banning, M., \& Gumley, V. A. (2012). Clinical nurses' expressions of the emotions related to caring and coping with cancer patients in Pakistan: A qualitative study. European Journal of Cancer Care, 21(6), 800-808. https://doi.org/10.1111/j.1365-2354.2012.01364.x

Bartram, T., Casimir, G., Djurkovic, N., Leggat, S. G., \& Stanton, P. (2012). Do perceived high performance work systems influence the relationship between emotional labour, burnout and intention to leave? A study of Australian nurses. Journal of Advanced Nursing, 68(7), 1567-1578. https://doi.org/10.1111/j.1365-2648.2012.05968.x

Bozionelos, G. (2016). Emotion work in the Arab context: Its relationship to job satisfaction and the moderating role of trust to the employer Psychological Reports, 119(1), 136-153. https://doi.org/10.1177/0033294116653949

Bozionelos, N., \& Kiamou, K. (2008). Emotion work in the Hellenic frontline services environment: How it relates to emotional exhaustion and work attitudes. International Journal of Human Resource Management, 19(6), 11081130. https://doi.org/10.1080/09585190802051410

Braun, V., \& Clarke, V. (2006). Using thematic analysis in psychology. Qualitative Research in Psychology, 3(2), 77-101. https://doi.org/10.1191/1478088706qp063oa 
Brooks, A., \& Devasahayam, T. (2010). Gender, emotions and labour marketsAsian and Western perspectives. Routledge.

Bulan, F. H., Erickson, R. J., \& Wharton, A. S. (1997). Doing for others on the job: The affective requirements of service work, gender, and emotional well-being. Social Problems, 44(2), 235-256. https://doi.org/10.2307/3096944

Central Bank of Sri Lanka. (2019). Annual report. https://www.cbsl.gov.lk/en/publications/economic-and-financial-reports/annualreports/annual-report-2019

Chu, K. H., Baker, M. A., \& Murrmann, S. K. (2012). When we are onstage, we smile: The effects of emotional labor on employee work outcomes. International Journal of Hospitality Management, 31(3), 906-915. https://doi.org/10.1016/j.ijhm.2011.10.009

Cottingham, M. D. (2015). Learning to "Deal" and "De-escalate": How men in nursing manage self and patient emotions. Sociological Inquiry, 85(1), 75-99. https://doi.org/10.1111/soin.12064

Cottingham, M. D., Erickson, R. J., \& Diefendorff, J. M. (2015). Examining men's status shield and status bonus: How gender frames the emotional labor and job satisfaction of nurses. Sex Roles, 72(7-8), 377-389. https://doi.org/10.1007/s11199-014-0419-Z

Cottingham, M. D., Johnson, A. H., \& Erickson, R. J. (2018). "I can never be too comfortable": Race, gender, and emotion at the hospital bedside. Qualitative Health Research, 28(1), 145-158. https://doi.org/10.1177/1049732317737980

De Silva, B. S. S., \& Rolls, C. (2010). Health-care system and nursing in Sri Lanka: An ethnography study. Nursing and Health Sciences, 12(1), 33-38. https://doi.org/10.1111/j.1442-2018.2009.00482.x

Delgado, C., Roche, M., Fethney, J., \& Foster, K. (2020). Workplace resilience and emotional labour of Australian mental health nurses: Results of a national survey. International Journal of Mental Health Nursing, 29(1), 35-46. https://doi.org/10.1111/inm.12598

Delgado, C., Upton, D., Ranse, K., Furness, T., \& Foster, K. (2017). Nurses’ resilience and the emotional labour of nursing work: An integrative review of empirical literature. International Journal of Nursing Studies, 70, 71-88. https://doi.org/10.1016/j.ijnurstu.2017.02.008

Dias, N. N. P., \& Bhadra, J. H. A. (2014). Using a double-edged sword: Emotional labour and the wellbeing of teachers in a National school in Sri Lanka. Proceedings of the 11th International Conference on Business Management Proceedings (pp. 330-343). http://dr.lib.sjp.ac.lk/handle/123456789/1601 Elliott, C. (2017). Emotional labour: Learning from the past, understanding the present. British Journal of Nursing, 26(19), 1070-1077. 
https://doi.org/10.12968/bjon.2017.26.19.1070

Erickson, R. J., \& Ritter, C. (2001). Emotional labor, burnout, and inauthenticity:

Does gender matter? Social Psychology Quarterly, 64(2), 146-163.

https://doi.org/10.2307/3090130

Evans, J. A. (2004). Bodies matter: Men, masculinity, and the gendered division of labour in nursing. Journal of Occupational Science, 11(1), 14-22. https://doi.org/10.1080/14427591.2004.9686527

Evers, C. W. (2018). The gendered emotional labor of male professional 'freesurfers' digital media work. Sport in Society, 1-16. https://doi.org/10.1080/17430437.2018.1441009

Fernando, W. D. A., \& Cohen, L. (2013). Exploring the interplay between Buddhism and career development: A study of highly skilled women workers in Sri Lanka. Work, Employment and Society, 27(6), 1021-1038. https://doi.org/10.1177/0950017013481084

Forseth, U. (2005). Gender matters? Exploring how gender is negotiated in service encounters. Gender, Work and Organization, 12(5), 440-459. https://doi.org/10.1111/j.1468-0432.2005.00283.x

Grandey, A. (2003). When the show must go on: Surface acting and deep acting as determinants of emotional exhaustion and peer-rated service delivery. The Academy of Management Journal, 46(1), 86-96. https://doi.org/10.5465/30040678

Grandey, A., \& Melloy, R. C. (2017). The state of the heart: Emotional labor as emotion regulation reviewed and revised. Journal of Occupational Health Psychology, 22(3), 407-422. https://doi.org/10.1037/ocp0000067

Gray, B. (2010). Emotional labour, gender and professional stereotypes of emotional and physical contact, and personal perspectives on the emotional labour of nursing. Journal of Gender Studies, 19(4), 349-360. https://doi.org/10.1080/09589236.2010.514207

Gray, B., \& Smith, P. (2009). Emotional labour and the clinical settings of nursing care: The perspectives of nurses in East London. Nurse Education in Practice, 9(4), 253-261. https://doi.org/10.1016/j.nepr.2008.08.009

Greenhalgh, J., Vanhanen, L., \& Kyngäs, H. (1998). Nurse caring behaviours. Journal of Advanced Nursing, 27(5), 927-932. https://doi.org/10.1046/j.13652648.1998.t01-1-00577.x

Han, S. S., Han, J. W., \& Kim, Y. H. (2018). Effect of nurses' emotional labor on customer orientation and service delivery: The mediating effects of work engagement and burnout. Safety and Health at Work, 9(4), 441-446. https://doi.org/10.1016/j.shaw.2017.12.001

Hellerawa, K. S. S. M., \& De Alwis, C. A. (2015). The nursing shortage impact on 
job outcome (The Case in Sri Lanka). Journal of Competitiveness, 7(3), 75-94. https://doi.org/10.7441/joc.2015.03.06

Hochschild, A. R. (1979). Emotion work, feeling rules, and social structure. American Journal of Sociology, 85(3), 551-575.

https://www.jstor.org/stable/2778583?seq=1

Hochschild, A. R. (1983). The managed heart: Commercialization of human feeling. University of California Press.

Holland, P. J., Allen, B. C., \& Cooper, B. K. (2013). Reducing burnout in Australian nurses: The role of employee direct voice and managerial responsiveness. International Journal of Human Resource Management, 24(16), 3146-3162. https://doi.org/10.1080/09585192.2013.775032

Humphrey, R. H., Pollack, J. M., \& Hawver, T. (2008). Leading with emotional labor. Journal of Managerial Psychology, 23(2), 151-168.

https://doi.org/10.1108/02683940810850790

Jackson, D., Hutchinson, M., Luck, L., \& Wilkes, L. (2013). Mosaic of verbal abuse experienced by nurses in their everyday work. Journal of Advanced Nursing, 69(9), 2066-2075. https://doi.org/10.1111/jan.12074

Jayasekara, R. S., \& Mccutcheon, H. (2006). The history of nursing services and education in Sri Lanka and the effects of developing professionalism.

Education, 45(10). 391-395. https://doi.org/10.3928/01484834-20061001-03

Jayasekara, R. S., \& Schultz, T. (2007). Health status, trends, and issues in Sri

Lanka. Nursing and Health Sciences, 9(3), 228-233.

https://doi.org/10.1111/j.1442-2018.2007.00328.x

Johnson, H. A. M., \& Spector, P. E. (2007). Service with a smile: Do emotional intelligence, gender, and autonomy moderate the emotional labor process? Journal of Occupational Health Psychology, 12(4), 319-333. https://doi.org/10.1037/1076-8998.12.4.319

Kailasapathy, P., \& Metz, I. (2012). Work - family conflict in Sri Lanka : Negotiations of exchange relationships in family and at work. Journal of Social Issues, 68(4), 790-813. https://doi.org/10.1111/j.1540-4560.2012.01776.x

Karimi, L., Leggat, S. G., Cheng, C., Donohue, L., Bartram, T., \& Oakman, J. (2016). Are organisational factors affecting the emotional withdrawal of community nurses? Australian Health Review, 41(4), 359-364. https://www.publish.csiro.au/ah/AH16027

Kelan, E. K., \& Nentwich, J. C. (2009). The value of seeing gender as a 'doing.' In M. F. Ozbilgin (Ed.), Equality, diversity and inclusion at work: A research companion (pp. 136-146). Edward Elgar Publishing Limited.

Kim, M. J., \& Han, S. Y. (2009). Relationship between emotional labor consequences and employees' coping strategy. Asia Pacific Journal of Tourism 
Research, 14(3), 225-239. https://doi.org/10.1080/10941660903023929

Kim, Y., \& Jang, S. J. (2018). Nurses' organizational communication satisfaction, emotional labor, and prosocial service behavior: A cross-sectional study. Nursing and Health Sciences, 1-8. https://doi.org/10.1111/nhs.12586

Kodikara, K. A. S. D., \& De Alwis, A. C. (2015). Emotional labour and job satisfaction: Case study on bank tellers (with special reference to Bank of Ceylon). Proceedings of the 2nd HRM Student Research Symposium. http://repository.kln.ac.lk/handle/123456789/12608

Korczynski, M. (2003). Communities of coping: Collective emotional labour in service work. Organization, 10(1), 55-79. https://doi.org/10.1177/1350508403010001479

Koster, S. (2011). The self-managed heart: Teaching gender and doing emotional labour in a higher education institution. Pedagogy, Culture and Society, 19(1), 61-77. https://doi.org/10.1080/14681366.2011.548988

Lawless, B. (2018). Documenting a labor of love: Emotional labor as academic labor. Review of Communication, 18(2), 85-97. https://doi.org/10.1080/15358593.2018.1438644

Liamputtong, P. (2008). Doing research in a cross-cultural context: Methodological and ethical challenges. In P. Liamputtong (Ed.), Doing cross-cultural research: Ethical and methodological perspectives (pp. 3-20). Springer.

Liu, H., Zou, H.-Y., Wang, H.-J., Xu, X., \& Liao, J.-Q. (2020). Do emotional labour strategies influence emotional exhaustion and professional identity or vice versa? Evidence from new nurses. Journal of Advanced Nursing, 76(2), $577-$ 587. https://doi.org/10.1111/jan.14266

Lively, K. J. (2013). Social and cultural influences: Gender effects on emotional labor at work and at home. In A. A. Grandey, J. M. Diefendorff, \& D. E. C. L. Rupp (Eds.), Emotional labour in the 21st century diverse perspectives on the psychology of emotional regulation at work (pp. 223-251). Routledge.

Martin, S. E. (1999). Police force or Police service? Gender and emotional labor. The Annals of the American Academy of Political and Social Science, 561(1), 111-126. https://doi.org/10.1177/000271629956100108

Maume, D. J., Jr. (1999). Glass ceilings and glass escalators: Occupational segregation and race and sex differences in managerial positions. Work and Occupations, 26(4), 483-509. https://doi.org/10.1177/0730888499026004005

Mishra, S. K., \& Bhatnagar, D. (2010). Linking emotional dissonance and organisational identification to turnover intention and emotional wellbeing: A study of medical representatives in India. Human Resource Management, 49(3), 401-419. https://doi.org/10.1002/hrm.20362

Nixon, A. E., Yang, L. -Q., Spector, P. E., \& Zhang, X. (2011). Emotional labor in 
china: Do perceived organizational support and gender moderate the process? Stress and Health, 27(4), 289-305. https://doi.org/10.1002/smi.1359

Nixon, D. (2009). "I can't put a smiley face on": Working-class masculinity, emotional labour and service work in the "New Economy." Gender Work and Organization, 16(3), 300-322. https://doi.org/10.1111/j.14680432.2009.00446.x

O'Donohoe, S., \& Turley, D. (2006). Compassion at the counter: Service providers and bereaved consumers. Human Relations, 59(10), 1429-1448. https://doi.org/10.1177/0018726706071648

Pandey, J., Sohani, S., \& Singh, M. (2018). Emotional labour of rural women in difficult geographies of an emerging economy: Narratives of Community Health Care Workers of India. International Journal of Work Organisation and Emotion, 9(2), 159-186. https://www.inderscience.com/offer.php?id=93302

Perera, S. V. B. P. Arachchige, B. J. H. (2014). Effect of emotional labour on emotional exhaustion of tellers in two Sri Lankan banks. Human Resource Management Journal, 2(1), 32-47. http://dr.lib.sjp.ac.lk/handle/123456789/3701

Perera, A., \& Kailasapathy, P. (2013). Emotional labour and work-family interference conflict of front-line employees. Sri Lankan Journal of Management, 18(1\&2), 1-21.

Pinto, I., \& Adikaram, A. S. (2020). Nightingales at risk: Occupational health and safety issues among the nursing officers in the healthcare industry. Proceedings of the 15th International Research Conference on Management and Finance 2020, 101-104. University of Colombo.

Private Health Services Regulatory Council. (2021). PHSRC listed nurses. http://www.phsrc.lk/pages_e.php?id=13

Pruitt, A. S. (2012). Emotional labor in a gendered occupation: The work of a female funeral director (Unpublished master's dissertation). University of Louisville. https://ir.library.louisville.edu/etd/1160 /

Qureshi, I., Ali, N., \& Randhawa, G. (2020). British South Asian male nurses' views on the barriers and enablers to entering and progressing in nursing careers. Journal of Nursing Management, 28(4), 892-902. https://doi.org/10.1111/jonm.13017

Roopalekha J. P. N., Latha, K. S., \& Prabhu, S. (2012). Occupational stress and coping among nurses in a super specialty hospital. Journal of Health Management, 14(4), 467-479. https://doi.org/10.1177/0972063412468977

Shani, A., Uriely, N., Reichel, A., \& Ginsburg, L. (2014). Emotional labor in the hospitality industry: The influence of contextual factors. International Journal of Hospitality Management, 37, 150-158. 
https://doi.org/10.1016/j.ijhm.2013.11.009

Simpson, R. (2004). Masculinity at work: The experiences of men in female dominated occupations. Work, Employment and Society, 18(2), 349-368. https://doi.org/10.1177/09500172004042773

Simpson, R. (2007). Emotional labour and identity work of men in caring roles. In P. Lewis \& R, Simpson (Eds.), Gendering emotions in organizations (pp, 5774). Palgrave MacMillan.

Simpson, R., Slutskaya, N., \& Hughes, J. (2011). Emotional dimensions of dirty work: Men's encounter with taint in the butcher trade. International Journal of Work Organisation and Emotion, 4(2), 195-212 http://www.inderscience.com/offer.php?id=44597

Søgaard, T. F., \& Krause-Jensen, J. (2020). Bouncer service work: Emotional labour and flexible masculinity. Journal of Organizational Ethnography, 9(1), 30-43. https://doi.org/10.1108/JOE-10-2018-0044

Stone, T., McMillan, M., Hazelton, M., \& Clayton, E. H. (2011). Wounding words: Swearing and verbal aggression in an inpatient setting. Perspectives in Psychiatric Care, 47(4), 194-203. https://doi.org/10.1111/j.17446163.2010.00295.x

Syed, J., \& Ali, F. (2013). Contextual emotional labor: An exploratory of Muslim female employees in Pakistan. Gender in Management, 28(4), 228-246. https://doi.org/10.1108/GM-01-2013-0007

Syed, J., Ali, F., \& Winstanley, D. (2006). In pursuit of modesty: Contextual emotional labour and the dilemma for working women in Islamic societies. International Journal of Work Organisation and Emotion, 1(2), 150-167. http://www.inderscience.com/offer.php?id=8819

Taylor, S., \& Tyler, M. (2000). Emotional labour and sexual difference in the airline industry. Work, Employment and Society, 14(1), 77-95. https://doi.org/10.1177/09500170022118275

Theodosius, C. (2008). Emotional labour in healthcare: The unmanaged heart of nursing. Routledge.

Theodosius, C., Koulouglioti, C., Kersten, P., \& Rosten, C. (2021). Collegial surface acting emotional labour, burnout and intention to leave in novice and pre-retirement nurses in the United Kingdom: A cross-sectional study. Nursing Open, 8(1), 463-472. https://doi.org/10.1002/nop2.649

Thisera, T. J. R., \& Bandara, W. B. M. A. P. L. (2018). The impact of emotional labor on emotional exhaustion of academics in state universities of Sri Lanka. Kelaniya Journal of Human Resource Management, 12(1), 101-109. http://doi.org/10.4038/kjhrm.v12i1.43

Thisera, T. J. R., \& Silva, D. P. A. K. H. (2017, March 17-18). The impact of 
emotional labour on emotional exhaustion of female nurses in Sri Lanka. Proceedings of the International Conference on Management Business And Economices. Kuala Lampur Malaysia.

Thomas, A., \& Abhyankar, S. (2014). A correlational study of emotional labour and health among nurses. Indian Journal of Health and Wellbeing, 5(2), 239-242.

Thurnell-Read, T., \& Parker, A. (2008). Men, masculinities and firefighting: Occupational identity, shop-floor culture and organisational change. Emotion, Space and Society, 1(2), 127-134. https://doi.org/10.1016/j.emospa.2009.03.001

Torland, M. (2011). Emotional labour and job satisfaction of adventure tour leaders: Does gender matter? Annals of Leisure Research, 14(4), 369-389. https://doi.org/10.1080/11745398.2011.639419

Vaccaro, C. A., Schrock, D. P., \& McCabe, J. M. (2011). Managing emotional manhood: Fighting and fostering fear in mixed martial arts. Social Psychology Quarterly, 74, 414-437. https://doi.org/10.1177/0190272511415554

Vincent, C., \& Braun, A. (2013). Being "fun" at work: Emotional labour, class, gender and childcare. British Educational Research Journal, 39(4), 751-768. https://doi.org/10.1080/01411926.2012.680433

Vithanage, S. D. (2015). Understanding the nature and scope of patriarchy in Sri Lanka: How does it operate in the institution of marriage? (Unpublished master's dissertation ). St. Cloud State University https://repository.stcloudstate.edu/socresp_etds/

Wanninayake, S. D. K. (2018, December 4-7). Nursing nurses' emotions: The coping strategies of Sri Lankan nurses. Proceedings of the $32^{\text {nd }}$ Australian and New Zealand Academy of Management Conference - 2018, 128-148. https://www.anzam.org/wp-content/uploads/2018/12/ANZAM-ConferenceProceedings-2018.pdf

Ward, J., \& McMurray, R. (2016). The dark side of emotional labour. Routledge.

Ward, J., \& McMurray, R. (2011). The unspoken work of general practitioner receptionists: A re-examination of emotion management in primary care. Social Science and Medicine, 72(10), 1583-1587. https://doi.org/10.1016/j.socscimed.2011.03.019

Ward, J., McMurray, R., \& Sutcliffe, S. (2020). Working at the edge: Emotional labour in the spectre of violence. Gender, Work and Organization, 27(1), 8297. https://doi.org/10.1111/gwao.12377

Watson, A., \& Ward, J. (2013). Creating the right "vibe": Emotional labour and musical performance in the recording studio. Environment and Planning A, 45(12), 2904-2918. https://doi.org/10.1068/a45619

Wharton, A. S. (1993). The affective consequences of service work: Managing 
emotions on the job. Work and Occupations, 20(2), 205-232.

https://doi.org/10.1177/0730888493020002004

Wharton, A. S. (1999). The psychosocial consequences of emotional labor.

American Academy of Political and Social Science, 561, 158-176.

https://www.jstor.org/stable/1049288?seq=1

Wharton, A. S. (2009). The sociology of emotional labor. Annual Review of

Sociology, 35, 147-165. https://doi.org/10.1146/annurev-soc-070308-115944

World Health Organization. (2020). World health statistics.

https://www.who.int/data/gho/publications/world-health-statistics

Yang, S. B., \& Guy, M. E. (2015). Gender effects on emotional labor in Seoul metropolitan area. Public Personnel Management, 44(1), 3-24. https://doi.org/10.1177/0091026014550491

Yarnal, C. M., Dowler, L., \& Hutchinson, S. (2004). Don't let the bastards see you sweat: Masculinity, public and private space, and the volunteer firehouse. Environment and Planning A, 36(4), 685-699. https://doi.org/10.1068/a35317

Zamanzadeh, V., Valizadeh, L., Sayadi, L., Taleghani, F., Howard, F., \& Jeddian, A. (2013). Emotional labour of caring for hematopoietic stem cell transplantation patients: Iranian nurses' experiences. Asian Nursing Research, 7(2), 91-97. https://doi.org/10.1016/j.anr.2013.04.004

Zhou, W., He, G., Wang, H., He, Y., Yuan, Q., \& Liu, D. (2015). Job dissatisfaction and burnout of nurses in Hunan, China: A cross-sectional survey. Nursing and Health Sciences, 17(4), 444-450. https://doi.org/10.1111/nhs.12213 